\title{
Ciência sucessora e a(s) epistemologia(s): saberes localizados
}

\author{
Juliana Góes
}

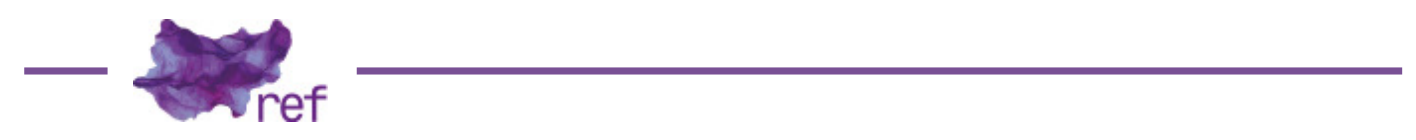

Resumo: O presente artigo é uma reflexão sobre a importância de uma nova forma de ciência, bem como sobre possíveis eixos para uma ciência feminista. Propõe-se, aqui, a substituição de um fazer científico neo-positivista por um modelo de ciência que entenda as formas de produzir saber oriundas de diferentes comunidades epistêmicas, que adote a objetividade como saberes localizados e que, ao invés de incorporar o liberalismo, seja comprometido com a libertação dos grupos subjugados. $O$ modelo proposto também inclui um novo objetivo para a ciência, que ao invés de buscar a lei universal do mundo, busque a tradução de diferentes realidades e permita uma relação de accountability entre os sujeitos de pesquisa.

Palavras-chave: epistemologia; feminismo; ciência; conhecimento.

\section{Successor Science and Epistemology(ies): Situated Knowledge}

Abstract: This article aims to promote a reflection about the importance of a new form of science, as well as about the possible principles for a feminist science. Here, it is proposed the replacement of the neo-positivist model for a new one, which understands the different forms to produce knowledge, adopts the idea of situated knowledge and that, instead of the liberalism, embodies the commitment with the social emancipation. This new model also should include a new objective: instead of to seek a universal law in the world, seeks the translation of different realities and allows the accountability between the subjects of research.

Keywords: epistemology; feminism; science; knowledge.

\section{Introdução}

Este trabalho' consiste em uma reflexão sobre um modelo de ciência (s) e epistelomogia (s) feminista (s), ou seja, sobre um projeto de uma "ciência sucessora" (Sandra HARDING, 1986 apud Donna HARAWAY, 2009). Ele é impulsionado por uma provocação de Cecília Sardenberg (2007). Mesmo reconhecendo que as críticas feministas da ciência são diversas, plurais e, muitas vezes, contraditórias, a autora defende a existência de um projeto de ciência feminista, que não seja realizado apenas por mulheres em um ou outro departamento/área de estudo, mas que substitua o modelo de ciência (neo)positivista.

Contudo, por que pensar em uma ciência sucessora? "O progresso da ciência" é uma frase bastante escutada atualmente e, em geral, refere-se ao gigantesco desenvolvimento tecnológico do século XX e XXI. Hoje, em diversas partes do mundo, a rotina do ser humano é cercada pela tecnologia (eletrônica e social): o acordar pelo despertador, as técnicas e máquinas usadas para plantio e colheita do alimento do café da manhã, os automóveis cada vez mais inteligentes, a expectativa de vida cada vez mais longa devido aos avanços na área da saúde. Esses progressos, sem dúvida nenhuma, causam espanto ao mesmo tempo que admiração (Lorraine CODE, 1993).

\footnotetext{
' Artigo produzido a partir da dissertação de mestrado "Corpo, autonomia e associativismo: a participação das prostitutas da Guaicurus", defendida no Programa de Pós-Graduação de Ciência Política da Universidade Federal de Minas Gerais.
} 
Porém, essa mesma ciência também desenvolveu tecnologias mortíferas. Ela permitiu a destruição de cidades inteiras através de bombas atômicas, a situação de risco atual que se encontra o nosso meio ambiente, o etnocídio e epistemicídio de diversas comunidades, etc. Além disso, há problemas simples do nosso dia a dia que, apesar de todo o progresso, não foram solucionados. Em um mundo onde se consegue falar ao vivo com pessoas de diferentes países, por exemplo, as mulheres ainda são as grandes responsabilizadas pelo trabalho doméstico, tendo de viver jornadas duplas e triplas de trabalho (Beatriz NASCIMENTO, 2006; Lélia GONZALEZ, 1983; Sueli CARNEIRO, 2011).

Por causa disto, para além de pensar no progresso da ciência, precisamos progredir dentro da ciência. $O$ atual modelo epistêmico hegemônico no ocidente é temporalmente, espacialmente e socialmente localizado, ou seja, ele foi construído em uma determinada época, refletindo o contexto social-histórico da mesma e do grupo que o produziu (Sondra FARGANIS, 1997). Este grupo consistia, majoritariamente, de homens brancos, ocidentais e burgueses, que se beneficiavam da estrutura de dominação colonial, racista, patriarcal e capitalista que se desenvolvia no século XVIII (CODE, 1993; FARGANIS, 1997). Isto significa que ele não é uma "lei natural" ou algo imutável. Da mesma forma como se produziram críticas às concepções anteriores ao seu surgimento, agora se produzem críticas que reivindicam uma ruptura da qual nasça um modelo epistêmico mais apropriado às necessidades do contexto social atual. E, olhando para as críticas feministas à ciência, espera-se que o novo modelo epistêmico reflita, ao invés dos interesses dos grupos dominantes, as perspectivas dos grupos dominados (HARDING, 1993; Diana GONZÁLEZ e Nelson RENGIFO, 2009; Breny MENDOZA, 2014).

É devido a esta necessidade que feministas, como Sardenberg (2007), têm discutido um novo modelo de ciência e é dentro desta problemática que este trabalho se insere. O desafio, contudo, não é buscar bases para uma nova epistemologia, e sim tratá-las no cenário feminista, onde as análises e propostas talvez tenham produzido mais divergências do que consensos. A própria autora não chega a definir eixos para a ciência feminisła, apesar de defender a existência dela. Este artigo, então, seguirá com um breve histórico das críticas aos padrões epistemológicos atuais, uma reflexão sobre como várias epistemologias podem construir um só modelo de ciência e uma exposição (nada neutra) dos principais temas-eixos da(s) epistemologia(s) feminista(s).

\section{Críticas feministas à ciência}

O modelo hegemônico atual ao qual me refiro é o (neo)positivismo. Ele é um projeto baseado em um método científico que busca garantir a objetividade e a neutralidade (HARDING, 1993; CODE, 1993; HARAWAY, 2009; Uma NARAYAN, 1997; FARGANIS, 1997; Elizabeth ANDERSON, 2000; Patricia COLLINS, 2002). A lógica que guia este método é racionalista e empiricista, ela tem como primazia a observação de relações causais entre variáveis que testam e constroem hipóteses deduzidas de uma teoria geral. A análise destas relações causais, neste método, deve procurar afirmações gerais e universais da realidade, ou seja, deve buscar se aproximar ao máximo possível do encontro das "leis que explicam o funcionamento do mundo" (HARDING, 1993; Sharlene HESSEBIBER, 2013). Assim, o conhecimento "digno" seria aquele "capaz de transcender as particularidades e se colocar de maneira universal" (CODE, 1993, p. 18, tradução minha). Por fim, a lógica do modelo (neo)positivista é exclusiva, ou seja, ela se coloca como a única correta e capaz de levar a algum tipo de conhecimento "real" do mundo, de forma que toda atividade intelectual que não segue seu método é invalidada (Maria MIES, 1998; HESSE-BIBER, 2013).

Nos anos 60, feministas em várias áreas da ciência começaram a denunciar o viés androcêntrico e sexista que os estudos da época continham, apontando que ele ia contra a objetividade e neutralidade proposta pelo próprio modelo (neo)positivista (HARDING, 1993; Helen LONGINO, 1993; SARDENBERG, 2007; HESSE-BIBER, 2013). Estas mulheres buscaram aprimorar o rigor metodológico com o objetivo de eliminar este viés. Elas definiram, então, como uma "boa pesquisa" aquela cuja correta aplicação do método científico impedia o viés do contexto patriarcal, e como "má pesquisa" a que contivesse o viés androcêntrico. Assim, sem romper com os princípios basilares do modelo (neo)positivista, estas feministas buscaram causar impacto na ciência e transformá-la (SARDENBERG, 2007).

Contudo, como diria Audre Lorde (2013), "as ferramentas do mestre nunca vão desmontar a casa do mestre". Transformar a ciência de forma que ela contribua para o fortalecimento das mulheres, utilizando as mesmas ferramentas que as subordinam, provou-se limitado para outras feministas. Estas começaram a fazer críticas mais radicais, reconstruindo os princípios fundamentais do modelo científico e atacando, inclusive, a própria existência de uma ciência (HARDING, 1993; HARAWAY, 2009; HESSE-BIBER, 2013).

As epistemologias que surgiram desse processo costumam ser divididas em três correntes a empiricista, a do standpoint e a pós-moderna (ANDERSON, 2000; Paula SILVA et al, 2005; HESSEBIBER, 2013). As feministas empiricistas se negam a abrir mão da posição de cientistas, da objetividade e da busca por um conhecimento empiricamente testado. Elas questionam, contudo, 
o fato de que sempre existirá um viés na pesquisa, pois a própria teoria já se constitui como tal. Há necessidade, portanto de reconhecer e controlar os vieses oriundos de preconceitos sexistas (HARDING, 1993; LONGINO, 1993).

Já o feminismo standpoint surge debaixo de grande influência marxista. Ele questiona os princípios fundamentais do modelo (neo)positivista e defende que uma ciência não pode ser neutra - ela precisa estar comprometida com a transformação social, com a eliminação do sistema de dominação. Porém, isso não significa negar a ciência, ou a produção de um conhecimento coerente com a realidade. Pelo contrário, quanto mais precisa a análise, melhor a intervenção no fenômeno. Assim, as feministas desta corrente reconstroem a ideia de objetividade, que ao invés de ser entendida como a separação da subjetividade, passa a ser definida como um processo crítico desta. Por fim, as feministas do standpoint defendem que a ciência deve partir do olhar dos grupos subjugados. Ao estar, simultaneamente, em uma posição de dominação e resistência, eles teriam uma perspectiva mais ampla da sociedade do que o grupo dominado, e, portanto, um privilégio epistêmico (Nancy HARTSOCK, 2003; HARDING, 1993).

A corrente pós-moderna é influenciada pela interpretação da realidade como uma construção de discursos/linguagens. Assim, nada é algo "em si", e sim discursos construídos. Nesse sentido, as feministas pós-modernas criticam inclusive a noção da categoria de mulher, que pressuporia uma experiência comum marcada pelo gênero. Elas utilizam das diferentes identidades - como lésbicas, negras, indígenas, trans, etc. - para desmitificar a ideia da essência única e compartilhada feminina. Em relação à ciência, estas feministas aplicam a ideia de que não existe um conhecimento "real", e sim um discurso construído. Dessa maneira, haveriam inúmeras perspectivas de conhecimento, marcadas, inclusive, pelas diferentes experiências das mulheres (ANDERSON, 2000; Judith BUTLER, 1988).

Essas classificações e definições, contudo, não são consensuais. Nelas, a corrente pósmoderna, por exemplo, costuma ser um agrupamento de diferentes e, às vezes, contraditórias teorias sob este mesmo rótulo. Além disso, há muitas feministas, consideradas empiricistas, que negam essa classificação (SARDENBERG, 2007). Porém, este mapeamento nos auxilia a marcar algumas diferenças importantes entre as epistemologias feministas no que tange à busca por um modelo de ciência feminista.

Esta busca costuma envolver maiores debates entre as empiricistas e as feministas do staindpoint, considerando que as pós-modernas não reivindicam uma ciência feminista (HARDING, 1993). Contudo, isso não quer dizer que não haja contribuição delas para a discussão. Keller, por exemplo, (1996 apud SARDENBERG, 2007) classifica as críticas da ciência de acordo com a distância que elas possuem do modelo (neo)positivistas. A autora atribui às feministas pós-modernas o maior radicalismo nesse mapa, pois elas seriam quem teceria críticas aos elementos mais basilares da ciência. Já as empiricistas são colocadas na posição de menos radicais, pois manteriam maior proximidade com o modelo hegemônico (a autora associa isso inclusive a uma orientação feminista liberal). O stainpoint ficaria, então, no meio termo.

Como este trabalho não se propõe a uma negativa da ciência, e sim à busca por um modelo feminista, mobilizarei, majoritariamente, feministas empiricistas e do staindpoint, analisando as diferentes bases e eixos que estas correntes debatem. Contudo, a contribuição das feministas pós-modernas não será excluída. Elas trazem questões importantes para a reflexão de uma possível ciência feminista, e suas críticas ajudaram e ajudam, inclusive, a aprimorar as demais linhas.

\section{Problemáticas em torno da criação de uma clência feminista}

Como dito acima, enquanto as feministas empiricistas buscam melhorar a aplicação dos métodos científicos, as feministas do standpoint reivindicam a modificação das bases do modelo científico positivista. Esta divergência pode ser vista na obra de Helen Longino (1993). Normalmente identificada como empiricista, a autora afirma que o standpoint recomenda que algumas perspectivas são epistemologicamente superiores que outras, mas falha ao explicar quais os critérios que devem ser usados para decidir ou justificar qual perspectiva é a melhor. Afinal, não existe apenas um grupo subjugado, mas um conjunto de relações de opressão que faz um determinado grupo ser, ao mesmo tempo, opressor e oprimido. O standpoint situa-se, para Longino, em um contexto de conflito entre conhecimentos. $E$, ao falhar na justificativa sobre qual deva ser considerado, ele recorre ao normativismo.

A autora propõe o abandono desta estratégia para combater o viés androcêntrico em prol da concentração dos esforços na multiplicação dos sujeitos do conhecimento. Ela defende que este não é produzido individualmente pois, para ser reconhecido, precisa ser validado por uma comunidade, no caso, a científica. Ampliar o número e o perfil de integrantes dela e reconhecer que a pesquisa não termina ao fim da observação e análise, e sim no diálogo com os demais pesquisadores, seria uma estratégia mais adequada para a transformação da ciência. Para garantir esse processo dialógico, Longino estabelece quatro critérios: 1- a existência de fóruns públicos de crítica das pesquisas, métodos e resultados; 2 - uma comunidade que não se limite 
a tolerar a dissidência, mas promova a mudança de posições através do processo crítico; 3 - a publicização dos padrões sobre os quais teorias, métodos e hipóteses são analisados e; 4 - a existência de igualdade de autoridade intelectual dentro da comunidade científica (LONGINO, 1993, p. 112-113). De acordo com Longino, portanto, não há necessidade de mudar os princípios básicos do modelo (neo)positivista, como a neutralidade e a objetividade.

Rompendo com este debate entre as empiricistas e as feministas do standpoint Narayan (1997), em artigo que critica o colonialismo do pensamento feminista do Norte Global e busca trazer dilemas não-ocidentais, defende que o positivismo não deve ser o principal inimigo da ciência feminista, e por isso os debates não devem se concentrar em mudá-lo ou não. Nas culturas não-ocidentais, este modelo epistêmico não tem tanta incidência social e, consequentemente, a busca pela separação entre fato e valor não é tão intensa. Estas culturas são marcadas por um forte tradicionalismo religioso, e não pela "religião da ciência". Tornar o positivismo o inimigo comum é uma tentativa colonialista de universalizar a experiência das mulheres ocidentais. Contudo, a autora se aproxima da corrente do standpoint ao discordar da avaliação de que não há necessidade de romper com os princípios positivistas. Estes não são neutros, pelo contrário, são alicerçados no liberalismo. Assim, o trabalho de Narayan vai no sentido contrário ao de Longino. Ela não só busca uma multiplicação de sujeitos na ciência, mas uma transformação da ciência. Narayan propõe que se reconheça a importância dos valores, bem como se afirme uma ciência onde não haja espaço para valores antifeministas. Estes é que devem ser o principal inimigo. Ela destaca que as mulheres que defendem o feminismo liberal resistem/negam o reconhecimento do liberalismo como um valor antifeminista a ser combatido. Mas como conhecedora do terror que o pensamento liberal foi no não-ocidente, através de práticas coloniais, Narayan entende que é impossível a emancipação da mulher dentro dele, posição da qual, como mulher negra e do Sul Global, compartilho.

Porém, fica aberta a pergunta: como definir os valores feministas e os seus opostos sem cair na prática colonial de universalizar as experiências das mulheres? A própria Narayan crítica, em sua obra, o modo como as feministas ocidentais definem, para o movimento, agendas que não correspondem à realidade de mulheres não ocidentais - como aborto e família. De acordo com a autora, o olhar das mulheres do Norte Global sobre as demais é caracterizado por uma "piedade" em relação à vivência destas em culturas marcadas pela religião. Esta "piedade" reflete o etnocentrismo que sustenta práticas colonialistas no feminismo. As mulheres não ocidentais, então, precisam combater tanto o patriarcado em suas culturas como a desvalorização das mesmas pelas mulheres ocidentais. A própria autora relata que, em diversos debates, sentiu-se compelida a interromper suas críticas sobre os problemas do sistema indiano de casamentos arranjados, para lembrar às ocidentais que as experiências das mulheres sob a crença no "amor romântico" também são problemáticas (NARAYAN, 1997, p. 280). Assim, há o medo de que, ao definir um modelo de ciência sucessora feminista e os valores da mesma, caia-se na contradição do projeto colonial.

Para isso, proponho pensarmos a epistemologia como um saber localizado; afinal, ela é uma teoria sobre o conhecimento (HARAWAY, 2009); FARGANIS, 1997; HESSE-BIBER, 2013). Por isso, no início deste trabalho falo de epistemologia(s) em um modelo de ciência. O conceito de saber localizado é oriundo de uma reconstrução da objetividade. Lorraine Code (1993) afirma que a existência de um viés androcêntrico e sexista na ciência mostra que a separação entre subjetividade e objetividade na pesquisa, não funciona. O pesquisador não consegue eliminar a si mesmo e apenas mascara sua subjetividade por meio da neutralidade. A noção de objetividade do modelo de ciência hegemônico, portanto é, na verdade, a adoção de uma subjetividade única, no caso aquela marcada pela comunidade acadêmica - homens brancos e ocidentais. Assim, a autora propõe trazer a subjetividade para a pesquisa, em um processo de constante reflexividade ${ }^{2}$ (apesar dela não utilizar este conceito). Assim, Code propõe que para se conseguir um conhecimento de fato objetivo, é necessário um processo dialético e crítico de constante análise da subjetividade do pesquisador.

Donna Haraway 2009 parte de críticas muito semelhantes às de Code. Porém, ela propõe a objetividade como visão parcial. Isto significa não um olhar semelhante ao de um deus onipresente, que tudo olha e nada vê, e sim como um olhar que parte de um corpo humano, localizado territorial, social e temporalmente. Assim, Haraway propõe uma visão corporificada, que produz um conhecimento corporificado e, como tal, localizado e parcial. A corporificação do conhecimento implica em se posicionar, ou seja, compreender que o saber é produzido por corpos e reconhecer a localização social e política que estes ocupam na estrutura. A objetividade é, então, um conhecimento localizado.

Ambas as autoras sinalizam que, para alcançar um conhecimento cada vez mais objetivo, é necessário abandonar a neutralidade e reconhecer a perspectiva parcial e subjetiva do pesquisador. Essa perspectiva não significa o mero conjunto de opiniões, mas sim a posição na estrutura de intersecção de classe, raça, gênero, etc. A subjetividade de Code é o contexto histórico

${ }^{2}$ Ver HESSE-BIBER, S. N. E. Feminist Research Practice. [S.I.]: Sage Publications, Thousand Oaks, CA, EUA, 2013. 
social e político no qual o pesquisador está inserido, noção paralela à posição que o corpo ocupa no tempo e espaço, de Haraway.

Porém, toda perspectiva é válida? Adota-se o relativismo? Para Code, a epistemologia feminista caminha, sim, para o relativismo. O projeto que a autora defende é de uma epistemologia localizada geograficamente, e, portanto, uma nova geografia da epistemologia (CODE, 1993, p. 39). Nesta nova geografia, todo conhecimento é relativo para alguém, ou seja, a partir do ponto de vista de alguém. Contudo, isso não significa, de acordo com Code, que é necessário adotar todo o pacote do relativismo, pois, para ela, as feministas não podem aceitar o cenário onde tudo é válido. Isto impede a crítica que leva à transformação social (se tudo é válido, nada pode ser negado). Para Code, portanto, se adota apenas parte do relativismo. Já Haraway defende que a ciência feminista deve romper com a dicotomia universalismo/relativismo. Estes são, de acordo com a autora, "irmãos gêmeos opostos". Afirmar a existência de uma única verdade tem o mesmo impacto que afirmar que tudo vale, pois ambos impedem a crítica. Localizar o saber, portanto, não significa dizer que existem várias perspectivas e que todas devem ser aceitas. Significa reconhecer que o conhecimento é parcial, e ao invés de se buscar leis universais e explicações globais, as comunidades devem traduzir o seu conhecimento uma para as outras. Assim, para Haraway, localizar o saber é uma alternativa ao relativismo. Ambas as autoras, portanto, compartilham da crítica à relativização, porém, elas se diferenciam na escolha de adotar uma opção já existente, mas de forma crítica, e na de criar uma terceira via no debate.

Retomando agora a nossa questão: como entender a epistemologia como um saber localizado pode contribuir para a construção de um modelo de ciência norteado por valores feministas, sem universalizar a experiência da mulher e cair no colonialismo? No debate que Haraway (2009) faz sobre a objetividade e o relativismo, ela traz um novo objetivo para a ciência. Como dito acima, ao invés de buscar a generalização de relações causais para sistemas globais, a autora trabalha com a noção de tradução. Ela utiliza da métafora da fotografia para explicar este conceito. Esta é uma visão parcial mediada pela tecnologia, que consiste na tradução desta visão para outras. Assim, uma fotografia não deve buscar ser a representação universal do mundo, e sim a tradução de uma visão localizada, de um saber localizado. Afirmar, portanto, que a epistemologia é um saber localizado no processo de busca de uma ciência não relativista, ou seja, onde não caibam valores antifeministas, significa romper com a ideia da adoção de um critério epistemológico único. A ciência deve traduzir as epistemologias das diferentes comunidades.

O problema dos valores, porém, ainda não foi abarcado, ou seja, como garantir que valores antifeministas não sejam tratados como "a epistemologia de uma comunidade"? Proponho, aqui, que adotemos, como valor da ciência, o compromisso com a emancipação das mulheres, considerando toda intersecção de classe, raça, orientação sexual, nacionalidade, etc. Entretanto, o conteúdo desta emancipação, bem como da análise dos sistemas de opressão, fica em aberto para ser construído pelas epistemologias das diferentes comunidades. Ou seja, busca-se uma ciência localizada em nossa época, que se oriente para as necessidades da atualidade e das comunidades locais, especificamente em relação à libertação dos grupos e corpos subjugados.

A emancipação de uma mulher do Sul Global não se dará da mesma forma que de uma mulher do Norte Global, assim como a emancipação da mulher negra ocorrerá de forma diferente daquela da mulher branca. Isso porque as resistências que levam à emancipação são diferentes, envolvem pautas distintas, relacionadas com a intersecção de opressões (COLLINS, 1998). Estas resistências são, muitas vezes, contraditórias. No Brasil, por exemplo, as mulheres negras sempre estiveram no mercado de trabalho, inclusive antes dos homens negros. Enquanto estes não conseguiam emprego formal, após a abolição, a mulher negra sustentava a família lavando roupa fora e fazendo outros serviços informais (NASCIMENTO, 2006; GONZALEZ, 1983; Sueli CARNEIRO, 2003; CARNEIRO, 2011). Com a entrada da mulher branca no mercado de trabalho, sem o rompimento da divisão sexual entre trabalho produtivo e reprodutivo, às mulheres negras foi entregue o papel do trabalho reprodutivo da família branca (GONZALEZ, 1983). Assim, a resistência da mulher branca ao papel doméstico, simbolizada pela disputa ao mercado de trabalho, relacionase tanto com a luta contra o patriarcado do homem branco como com a exploração da mulher negra.

Assim, só é possível entender do que se emancipar e as resistências para tal se as mulheres estiverem em constante diálogo umas com as outras, ou seja, fazendo o constante exercício crítico de avaliar sua localização social, reconhecer a posição uma das outras e traduzir-se. Uma ciência engajada com a emancipação da mulher não deve referir-se a um grupo específico. Pelo contrário, deve-se compreender que "uma só será livre, quando todas forem". As comunidades e os grupos não estão isolados, nem os sistemas de opressão. Maria Mies (1998), por exemplo, mostra como a housewifization da mulher branca ocidental se deu conjuntamente com a escravização das mulheres negras e indígenas, bem como atribuição do trabalho manual para estas. $O$ valor da ciência, portanto, deve ser o compromisso com a emancipação, substituindo o liberalismo. Mas só 
a produção de epistemologias localizadas não é o suficiente para tal. O processo dialógico, a articulação em rede destas epistemologias e saberes, que traduzirão realidades umas para as outras, é fundamental no modelo de ciência aqui exposto ${ }^{3}$. As resistências não podem ser individuais ou de grupos específicos, elas precisam ser coletivas.

Por fim, como garantir que, dentro de uma comunidade, a ciência seja comprometida com os corpos subjugados e não com os exploradores? Retomo aqui o debate sobre o privilégio epistêmico do feminismo standpoint. Este, provavelmente, é um dos pontos mais polêmicos das linhas epistemológicas feministas atuais. Como exposto na breve retomada da história das críticas feministas à ciência, a linha do standpoint afirma que, ao estar simultaneamente em uma posição de dominação e resistência, os grupos subjugados teriam uma perspectiva mais ampla da sociedade do que o grupo dominante, e, portanto, um privilégio epistêmico. Aprofundando este conceito, o que as mulheres desta linha de pensamento consideram é que as diferenças de gênero trariam experiências diferentes para homens e mulheres, que se concretizariam na dominação dos primeiros sobre as segundas. As mulheres seriam empurradas à margem da sociedade, e teriam de aprender tanto a lógica do grupo dominado, por estar neste espaço, quanto do dominante, por ter de sobreviver a ele. Assim, elas teriam uma perspectiva da sociedade mais completa, e o estudo a partir desta perspectiva seria o que se encontraria de mais radical para o fim das opressões (HARTSOCK, 2003; HARAWAY, 2009; HARDING, 1993; NARAYAN, 1997; COLLINS, 1998; COLLINS, 2002; ANDERSON, 2000; SARDENBERG, 2007; SILVA, et al 2005; GONZÁLEZ e RENGIFO, 2009). Esta ideia tem como base o privilégio epistêmico de Marx. Ele considerava que os proletários eram tanto marginais quanto centrais na sociedade. Marginais por estarem sob forças de dominação e centrais porque eles eram fundamentais para a sustentação do capitalismo. Ocupar estas duas posições lhes dariam uma perspectiva mais ampla da sociedade do que o grupo burguês, bem como uma perspectiva mais revolucionária, pois os proletários não teriam interesse na manutenção do sistema de dominação (HARTSOCK, 2003).

Duas críticas comuns são feitas à noção de privilégio epistêmico. A primeira refere-se a como definir qual o grupo que terá este privilégio (LONGINO, 1993; Bat-Ami Bar ON, 1993). A segunda crítica consiste na romantização dos grupos subjugados (COLLINS, 1998; HARDING, 1993; NARAYAN, 1997). On (1993) resume e desenvolve estas duas críticas no artigo Marginality and epistemic privilege. Ela relembra que, em Marx, a marginalização, sozinha não é uma condição necessária e suficiente para o privilégio epistêmico, pois ele também considera a centralidade no sistema. Os desempregados, por exemplo, eram marginalizados, mas não ocupavam um papel central na produção, por isso não tinham o privilégio epistêmico. De acordo com a autora, considerar que as mulheres ocupam essa posição de centralidade e marginalização simultânea no sistema patriarcal implica em ter apenas este como objeto de desmanche. Os demais sistemas de poder, como o de classe e o racial, seriam desconsiderados. O reconhecimento de múltiplos centros de poder, portanto, impediria que as mulheres estivessem, simultaneamente, nas duas posições necessárias e suficientes para o privilégio epistêmico. Para On, sustentar este conceito demandaria escolher um grupo subalterno que ocupe a posição central no sistema a ser combatido, tarefa impossível.

Mesmo que se tivesse apenas um centro de poder, de acordo com a autora, não se fugiria da romantização dos grupos subalternos. Modificando a noção de Marx, as feministas do standpoint utilizaram o conceito de privilégio epistêmico mais como uma reivindicação dos grupos subjugados por espaço do que de um conceito epistêmico de fato. As mulheres declararam que vivem sob a dialética, tanto de opressão quanto de resistência, e chamam atenção para este segundo ponto, para se colocarem como sujeitas do conhecimento. Ou seja, elas se afastam da noção de vítimas e objetos do saber e se colocam como agentes. Assim, se fala da marginalização não como uma relação de sustentação do sistema, mas como uma distância até o centro. $E$, quanto mais longe desse centro, mais resistência necessária para sobreviver. Contudo, a autora pontua que as resistências dos grupos subjugados não são perfeitas ou puras, e idealizá-las atrapalharia o conhecimento objetivo. Além disso, como "estratégia de voz" dos grupos subalternos, o privilégio epistêmico seria problemático. Ele reivindicaria a autorização destes grupos a falarem por si e de si através da desautorização dos outros. Porém, na situação de marginalização, estes grupos não teriam poder de desautorizar o grupo dominante. Portanto, para On, não se tem como sustentar a ideia de privilégio epistêmico.

A primeira crítica já foi debatida por muitas feministas do standpoint. A busca por um grupo epistemologicamente privilegiado não faz mais sentido dentro desta linha. Uma das precursoras do uso da estratégia epistemológica de Marx na teoria feminista é Nancy Hartsock (2003). Ela justifica seus argumentos na experiência psicanalítica de "uma mulher" e acaba por universalizar esta experiência, sem reconhecer as diferenças promovidas pela intersecção de opressões. Outras feministas standpoint, porém, incorporaram estas críticas nas análises, permitindo o reconhecimento de não apenas um grupo subjugado, mas de vários. Além disso, a conceitualização de objetividade,

\footnotetext{
${ }^{3}$ É por isso, inclusive, que compactuo com Narayan na defesa de que a emancipação da mulher e o liberalismo são incompatíveis.
} 
como saber localizado, permite utilizar a perspectiva, o standpoint, por meio de trocas de saberes parciais entre estes diversos grupos. Assim, se mantém a noção de privilégio epistêmico, articulada com o reconhecimento das várias localizações sociais na qual os corpos estão (COLLINS, 2002; HARAWAY, 2009; HARDING, 1993; GONZÁLEZ e RENGIFO, 2009; MENDOZA, 2014).

A segunda crítica tem sido extremamente debatida e aprofundada. O fato de ser um corpo subjugado não significa que o indivíduo será contra o sistema de dominação, pois é necessário considerar a ideologia que o sustenta (NARAYAN, 1997). Este problema vem acompanhado da definição de quem é autorizado a falar. O privilégio epistêmico faria que apenas os corpos subjugados pudessem falar sobre a sua opressão? Além disso, se nem todos os corpos subjugados são críticos às suas experiências de dominação, como definir quem tem autorização para falar? 0 problema da política da identidade reside justamente neste ponto. Apenas o fato de ser, quer dizer, uma idealização do que isto representa, é suficiente para tornar um corpo marginalizado representante do coletivo? E, se ao invés de focarmos na idealização identitária, reconhecermos a autorização com base na ideologia, não corremos o risco de que sujeitos de grupos opressores usurpem a voz dos grupos dominados, como sempre ocorreu na história? (COLLINS, 2002; COLLINS, 1998; HARAWAY, 2009; HARDING, 1993; NARAYAN, 1997; NASCIMENTO, 2006; ON, 1993).

Alternativas para esta problemática são encontradas nas obras de Patricia Hills Collins (1998) e de Haraway (2009). Collins, ao fazer um levantamento do que seria o pensamento feminista negro, se depara com as perguntas acima, ainda mais porque, neste, a experiência vivida tem um papel central. A saída da autora consiste na compreensão do papel de centralidade das mulheres negras sobre o feminismo negro. Centralidade, contudo, não significa exclusividade, e sim diálogo. A autora afirma que, para as feministas negras, o isolamento referente a outros grupos sociais seria o mesmo que manter o pensamento negro à margem. Assim, ela trabalha com a ideia de coalizão, ou seja, todos podem (e devem) produzir na perspectiva do feminismo negro. Porém, não há como se produzir esta perspectiva sem a presença das mulheres negras. Por isso, para que outros grupos façam parte desta coalizão, precisam estar constantemente em diálogo com estas mulheres, entendendo o papel de centralidade delas e refletindo constantemente sobre sua própria posição. Assim, Collins foge da vinculação meramente ideológica do privilégio epistêmico. A autora também argumenta que nem todas as mulheres negras são feministas negras, devido aos problemas da ideologia dominante, já abordados. A saída da autora é entender o feminismo negro como uma construção coletiva, que passa pelo processo de diálogo dentro da comunidade que tem como centro as mulheres negras. Dessa forma, ela desloca a idealização do privilégio epistêmico, que consiste na resistência individual, para a construção coletiva e crítica da resistência.

Posicionamento semelhante encontra-se em Haraway (2009). No mesmo trabalho onde articula a ideia de saberes localizados, a autora afirma que uma objetividade a partir do reconhecimento da corporificação do pesquisador significa que não se procura assumir a posição de identidade de quem se pesquisa; ela significa, na verdade, uma conexão parcial. "Não há maneira de 'estar' simultaneamente em todas, ou inteiramente em uma, das posições privilegiadas (subjugadas). A procura por uma tal posição 'inteira' e total é a procura pelo objeto perfeito, fetichizado, da história oposicional” (HARAWAY, 2009, p. 27). Assim, ela estabelece que não apenas o sujeito que produz a pesquisa é corporificado, mas também aquele que se estuda. A objetividade, dentro da lógica do privilégio epistêmico, é, portanto, o reconhecimento da diferença entre estes corpos, a busca pela perspectiva do subjugado, mas sem idealizá-lo ou tentando torna-se ele, e sim mantendo sua posição e dialogando a partir dela. Tentar tornar-se o outro implica em cair no mesmo erro, na neutralidade, ou seja, em esconder a própria subjetividade (COLLINS, 2002; CODE, 1993; HARAWAY, 2009; COLLINS, 1998).

Retomando, portanto, o objetivo de pensar em um modelo de ciência feminista sucessora, é possível trabalhar sob um modelo que comporte epistemologias de várias comunidades. Estas, porém, devem estar guiadas pelo compromisso com a transformação social e com a emancipação da mulher, em substituição ao liberalismo. Para isso, elas precisam ter como norte a perspectiva dos grupos subalternos e articularem-se em rede de traduções. Ou seja, a produção do conhecimento (e da resistência) deixa de ser a experiência local ou individual e sim o diálogo entre os diferentes grupos subjugados. Por fim, um exemplo prático desta proposta nos é oferecida por Patricia Hills Collins (2002) no livro Black feminist thought: Knowledge, consciousness, and the politics of empowerment. A autora não busca pensar em uma epistemologia universal, e sim traduzir a epistemologia do feminismo negro para outras comunidades, mostrando como este também é um saber localizado. Collins convida, inclusive, outros grupos subalternos a traduzirem suas epistemologias e dialogarem.

Nessa obra, ela também nos traz duas últimas contribuições para o modelo de ciência proposto. A autora destaca quatro eixos da epistemologia do feminismo negro: a experiência vivida, o diálogo, a ética do cuidado e a ética do accountability. Collins destaca que existe uma diferença entre conhecimento e sabedoria (wisdom). Um letrado que leva uma arma para matar uma barata, 
por exemplo, pode ter conhecimento, mas não sabedoria. Viver sobre a intersecção de opressões obriga as pessoas a desenvolverem sabedoria para sobreviver. Essa sabedoria gerada pela experiência vivida é importante para fundamentar as pesquisas. Já a ideia de diálogo consiste na troca do distanciamento "objetivo" do modelo hegemônico pela conectividade. Esta implica no reconhecimento de dois sujeitos e a produção de conhecimento com base na conversa entre eles, e não no discurso de um sobre o outro. Esse diálogo também deve ser feito com a comunidade. A ética do cuidado envolve o reconhecimento da unicidade do indivíduo, a emoção e a empatia. Os indivíduos, de acordo com a autora, são como pedaços únicos em uma colcha de retalho, que junto fazem um todo - cada um possui uma energia própria. Vislumbrar esta rede na pesquisa, junto com o reconhecimento da emoção do pesquisador e a do outro com quem se trabalha, através da empatia, é a aplicação da ética do cuidado. Nesta ética, razão e emoção não se separam. Por fim, a ética do accountability implica na responsabilização do pesquisador pelo que ele produz, tanto na comunidade quanto na vida pessoal.

A ética do cuidado e a do accountability podem ser aplicadas para além da relação entre pesquisador e quem se pesquisa. Elas podem (e devem) ser guias da relação dialógica entre epistemologias localizadas. A ética do cuidado traz a dimensão de solidariedade entre os diferentes grupos subalternos e suas perspectivas, reforçando a importância de uma unidade para a emancipação, sem ignorar a intersecção das diferentes opressões. Assim, não há necessidade de competição sobre qual é o grupo que terá um privilégio epistêmico. É possível criar uma lógica para além desse padrão competitivo e que seja guiada pela solidariedade. A ética do accountability reforça a importância de se ter um valor guia pela transformação social. A validação do conhecimento não deve ocorrer pela observação individual ou por uma comunidade pequena e praticamente isolada, como a científica. Ela deve ocorrer na rede de traduções e diálogo dos diversos grupos subalternos, onde o pesquisador poderá ter uma relação de accountability da sua produção.

\section{Conclusão: desenho de uma ciência feminista}

Até aqui expus reflexões e propostas sobre um modelo de ciência sucessora, que seja guiado pelas epistemologias localizadas. Estas reflexões, como dito na introdução, foram provocadas principalmente por Sardenberg (2007), que defende já ser "chegada a hora de afirmarmos que o que fazemos, quando fazemos tudo isso (pesquisas a partir das críticas feministas à ciência), é também o fazer de uma ciência feminista" (SARDENBERG, 2007, p. 29). Assim, mesmo reconhecendo toda a pluralidade e as contradições das correntes epistemológicas feministas, ela propõe o desafio da unidade, que promova uma ciência que seja feita não só pelas mulheres, mas pela sociedade em geral. Contudo, Sardenberg não especifica em seu trabalho quais seriam os eixos e orientações desta ciência, desafio que foi incorporado neste trabalho. Para concluir, portanto, farei um resgate de quais seriam estes eixos e seus desafios.

O modelo aqui proposto é extremamente influenciado pelas feministas standpoint, porém não deixa de dialogar com críticas das feministas pós-modernas e empiricistas (e, em alguns casos, incorporá-las). Após compreender que a ciência "neutra" é, na verdade, uma ciência liberal, e que o liberalismo é incompatível com a emancipação das mulheres, propõe-se um modelo de ciência que tenha como valor o combate aos sistemas opressores, ou seja, uma ciência politizada, que fundamente uma prática política cientificizada (SARDENBERG, 2007). Neste modelo, porém, não há uma epistemologia única, e sim, epistemologias socialmente localizadas, que devem corresponder às demandas de transformação dos grupos subjugados. Por fim, propõe-se que a produção de conhecimento, bem como a definição do que é a emancipação das mulheres, sejam entendidas como processos dialógicos contínuos entre diversas comunidades e grupos subalternos. Esse diálogo consiste no traduzir-se um para o outro e buscar, através da orientação da solidariedade e não da competitividade, a emancipação de todas e todos. O accountability da ciência deve ser possível, portanto, para todas as comunidades, indo contra a prática atual de validar o conhecimento apenas no "espaço científico". Este accountability significa também que a proposta inclui o abandono da ideia de que o conhecimento é produzido individualmente e passa a entendê-lo como prática coletiva.

Assim, os eixos que guiam este modelo partem das críticas feministas aos sistemas explicativos globais, à "objetividade neutra" (substuindo-a por uma objetividade localizada e corporficada), ao colonialismo, ao liberalismo e ao privilégio epistêmico. O conceito de interseccionalidade também é base deste modelo (CARNEIRO, 2003; CARNEIRO, 201 1; COLLINS, 2002; COLLINS, 1998; Lélia GONZALEZ, 1983; NASCIMENTO, 2006; NASCIMENTO, 2006; GONZALEZ, 1988; GONZALEZ, 2011).

Todavia, a compreensão de que a epistemologia é um saber localizado impede o modelo proposto de se considerar universal ou eterno. Ele atenderia apenas algumas necessidades dos grupos subalternos (principalmente ocidentais) dos tempos atuais. Assim, à medida que os debates se aprofundarem e as necessidades mudarem, o modelo proposto se modificaria. De imediato, aponto a importância do modelo de incorporar mais perspectivas do Sul Global, pois o pouco 
reconhecimento das epistemologias do Sul e do mundo não-ocidental tornam o pensar em um modelo de ciência sucessora limitado às contribuições do Norte Global. Sem este reconhecimento, o privilégio epistêmico pode se tornar apenas um instrumento para incorporar poucos elementos dos grupos subalternos como forma de legitimar discursos. Por exemplo, há autores que não dialogam com mulheres negras, mas utilizam alguns poucos elementos do feminismo negro para legitimarem seus discursos como decoloniais (Ochy CURIEL, 2007).

Por fim, apesar de não concordar com as propostas de transformação da ciência apresentadas por Longino (1993), é importante considerar o apontamento da autora sobre a aplicação das propostas epistemológicas nas ciências naturais. Este apontamento é de extrema importância para reflexões futuras. Os debates aqui tratados se aplicam a fenômenos sociais e pesquisas onde há um sujeito pesquisador e um sujeito de pesquisa. A aplicação destes debates no estudo de fenômenos naturais incorporaria novos desafios. Por fim, acredito que seja importante a constante reflexão sobre o tema, pois precisamos pensar para além do "progresso da ciência". Precisamos andar em direção a uma ciência "em progresso".

\section{Referências}

ANDERSON, Elizabeth. "Feminist epistemology and Philosophy of Science". Stanford Encyclopedia of Philosophy. 2000. Disponível em: https://plato.stanford.edu/entries/feminism-epistemology/. Acesso em 24/12/2016.

BUTLER, Judith. "Performative Acts and Gender Constitution: an essay in phenomenology". Theatre Journal, v. 40, n. 4, p. 519-531, dezembro, 1988. Disponível em: https://www.jstor.org/stable/ 3207893?seq=1 \#metadata_info_tab_contents. Acesso em 24/12/2016.

CARNEIRO, Sueli. "Enegrecer o feminismo: a situação da mulher negra na América Latina a partir de uma perspectiva de gênero". In: ASHOKA EMPREENDEDORES SOCIAIS. Racismos contemporâneos. Rio de Janeiro: Takano Editora, 2003, p. 49-58.

CARNEIRO, Sueli. Racismo, sexismo e desigualdade no Brasil. São Paulo: Selo Negro, 2011.

CODE, Lorraine. "Taking subjectivity into account". In: ALCOFF, Linda; POTTER, Elizabeth. Feminists epistemologies. New York and London: Routledge, 1993, p. 15-48.

COLLINS, Patricia Hills. "La política de pensamento feminista negro". In: NAVARRO, Marysa; STIMPSON, Catherine. ¿Que són los estudios de las mujeres? Buenos Aires: Fonte de Cultura Econômica, 1998, p. 253-313.

COLLINS, Patricia Hills. Black feminist thought: Knowledge, consciousness, and the politics of empowerment. London: Routledge, 2002.

CURIEL, Ochy. "Crítica poscolonial desde las prácticas políticas del feminismo antirracista". Nómadas, Colombia, v. 26, p. 92-101, 2007. Disponível em: http://www.redalyc.org/pdf/1051/ 105115241010.pdf. Acesso em 24/12/2016.

FARGANIS, Sondra. "O feminismo e a reconstrução da ciência social". In: JAGGAR, Alison; BORDO, Susan. Gênero, corpo e conhecimento. Rio de Janeiro: Rosa dos Tempos, 1997. p. 224-240.

GONZÁLEZ, Diana Carrillo; RENGIFO, Nelson Santiago Patarroyo. "Una propuesta de resistencia epistemológica". In: GONZÁLEZ, Diana Carrillo; RENGIFO, Nelson Santiago Patarroyo. Derecho, interculturalidad y resistencia étnica. Bogotá: Universidad Nacional de Colombia, 2009, p. 9-20.

GONZALEZ, Lélia. "Racismo e sexismo na cultura brasileira". In: SILVA, Luiz António et al. Movimentos sociais urbanos, minorias e outros estudos. Brasília, ANPOCS, n. 2, p. 223-244, 1983. (Ciências Sociais Hoje)

GONZALEZ, Lélia. "A categoria político-cultural de amefricanidade". Tempo Brasileiro, Rio de Janeiro, n. 92/93, p. 69-82, jan/jun, 1988.

GONZALEZ, Lélia. "Por um feminismo Afro-latino-Americano". In: CÍRCULO PALMARINO. Caderno de Formação Política do Círculo Palmarino: Batalha de Ideias, Brasil, 201 1, p. 12-21. Disponível em: https://disciplinas.stoa.usp.br/pluginfile.php/271077/mod_resource/content/1/ Por\%20um\%2Ofeminismo\%20Afro-latino-americano.pdf. Acesso em 01/1̄1/2013.

HARAWAY, Donna. "Saberes localizados: a questão da ciência para o feminismo e o privilégio da perspectiva parcial". Cadernos Pagu, Campinas, n. 5, p. 7-41, 2009. Disponível em: http:// www.bibliotecadigital.unicamp.br/document/?down=51046. Acesso em 24/12/2016. 
HARDING, Sandra. "Rethinking standpoint epistemology: What is 'strong objectivity'?" In: ALCOFF, Linda; POTTER, Elizabeth. Feminist epistemologies. New York and London: Routledge, 1993, p. 4982.

HARTSOCK, Nancy. "The Feminist Standpoint: Toward a Specifically Feminist Historical Materialism". In: MCCANN, Carole; SEUNG-KYUNG, Kim. Feminist Theory Reader: Local and global perspectives. New York and London: Routledge, 2003. p. 292-307.

HESSE-BIBER, Sharlene Nagy. Feminist Research Practice: A Primer. Los Angeles: Sage Publications, 2013.

LONGINO, Helen. "Subjects, power, and knowledge: description and prescription in feminist philosophies of science". In: ALCOFF, Linda; POTTER, Elizabeth. Feminists epistemologies. New York and London: Routledge, 1993, p. 101-120.

LORDE, Audre. Mulheres negras: as ferramentas do mestre nunca irão desmantelar a casa do mestre, 2013. Disponível em: https://www.geledes.org.br/mulheres-negras-as-ferramentas-do-mestrenunca-irao-desmantelar-a-casa-do-mestre/. Acesso em 24/12/2016.

MENDOZA, Breny. "La epistemología del sur, la colonialidad del género”. In: MIÑOSO, Yuderkys Espinosa; CORREAL, Diana Gómez; MUÑOZ, Karina Ochoa. Tejiendo de otro modo: Feminismo, epistemología y apuestas descoloniales en Abya Yala. Colombia: Universidad del Cauca, 2014, p. 91-104.

MIES, Maria. Patriarchy and Accumulation on a World Scale: Women in the International Division of Labour. London and New York: Zed Books Ltd. 1998.

NARAYAN, Uma. "O projeto da epistemologia feminista: perspectivas de uma feminista não ocidental". In: JAGGAR, Alison; BORDO, Susan. Gênero, corpo e conhecimento. Rio de Janeiro: Rosa dos Tempos, 1997, p. 276-290.

NASCIMENTO, Beatriz. "Por uma história do homem negro". In: RATTS, Alex. Eu sou atlântica: sobre a trajetória de vida de Beatriz Nascimento. São Paulo: Instituto Kuanza, 2006, p. 93-97.

NASCIMENTO, Beatriz. "A mulher negra no mercado de trabalho". In: RATTS, Alex. Eu sou atlântica: sobre a trajetória de vida de Beatriz Nascimento. São Paulo, Instituto Kuanza, 2006, p. 102-106.

ON, Bat-Ami Bar. "Marginality and epistemic privilege". In: ALCOFF, Linda; POTTER, Elizabeth. Feminists epistemologies. New York and London: Routledge, 1993, p. 83-100.

SARDENBERG, Cecília. Da Crítica Feminista à Ciência a uma Ciência Feminista?. 2007. Disponível em: $\quad$ https://repositorio.ufba.br/ri/bitstream/ri/6875/1/ Vers\%C3\%A30\%20FInal\%20Da\%20Cr\%C3\%ADtica\%20Feminista.pdf. Acesso em 24/12/2016.

SILVA, Paula, et al. "Acerca do debate metodológico na investigação feminista". Revista Portuguesa Ciência Desportiva [online], v. 5, n. 3, p. 358-370, 2005. Disponível em: http://www.scielo.mec.pt/ scielo.php?script=sci_arttext\&pid=\$1645-05232005000300012\&lng=pt\&nrm=iso. Acesso em 24/ $12 / 2016$.

\section{Juliana Morais de Góes (iD) 0000-0003-1728-353X}

Doutoranda na University of Massachusetts

Mestre em Ciência Política na Universidade Federal de Minas Gerais. Graduada em Ciência Política pela Universidade de Brasília. Atualmente pesquisa movimentos sociais, raça e gênero e concorre ao certificado em Africana Studies pelo W.E.B. Du Bois Department of Afro-American Studies (UMass Amherst). Já integrou o Conselho Nacional de Promoção da lgualdade Racial e o Comitê de Acompanhamento da Plano Nacional de Política para as Mulheres (PNPM), pelo Ministério das Comunicações. Participou, também, do Projeto Democracia Participativa - PRODEP e do Grupo de Pesquisa sobre Democracia e Desigualdades - Demodê.

University of Massachusetts

702 Thompson Hall, 200 Hicks Way, UMass

01003 - Amherst, MA, United States of America

(413) 545-0577

jgoes@umass.edu 


\section{COMO CITAR ESSE ARTIGO DE ACORDO COM AS NORMAS DA REVISTA}

GÓES, Juliana. "Ciência sucessora e a (s) epistemologia (s): saberes localizados". Revista Estudos Feministas, Florianópolis, v. 27, n. 1, e48373, 2019.

\section{CONTRIBUIÇÃO DE AUTORIA}

Não se aplica

\section{FINANCIAMENTO}

Bolsa do CNPq.

CONSENTIMENTO DE USO DE IMAGEM

Não se aplica

APROVAÇÃO DE COMITÊ DE ÉTICA EM PESQUISA

Não se aplica

\section{CONFLITO DE INTERESSES}

Não se aplica

\section{LICENÇA DE USO}

Este artigo está licenciado sob a Licença Creative Commons CC-BY. Com essa licença você pode compartilhar, adaptar, criar para qualquer fim, desde que atribua a autoria da obra.

\section{HISTÓRICO}

Recebido em: 24/12/2016.

Aprovado em 29/05/2018. 